\title{
Experimental analysis of the effect of standards on compliance and performance
}

\section{Citation}

Boussalis, Constantine, Yuval Feldman, and Henry E. Smith. 2017. "Experimental Analysis of the Effect of Standards on Compliance and Performance." Regulation \& Governance. doi:10.1111/ rego.12140.

\section{Published Version}

10.1111/rego.12140

\section{Permanent link}

http://nrs.harvard.edu/urn-3:HUL.InstRepos:32136183

\section{Terms of Use}

This article was downloaded from Harvard University's DASH repository, and is made available under the terms and conditions applicable to Open Access Policy Articles, as set forth at http:// nrs.harvard.edu/urn-3:HUL.InstRepos:dash.current.terms-of-use\#OAP

\section{Share Your Story}

The Harvard community has made this article openly available.

Please share how this access benefits you. Submit a story.

Accessibility 


\title{
An Experimental Analysis of the Effect of Specificity on Compliance and Performance
}

\author{
Constantine Boussalis, Trinity College, Dublin \\ Yuval Feldman, Bar-Ilan University \\ Henry E. Smith, Harvard Law School*
}

Laws can be written along a spectrum of specificity, ranging from vague standards to more detailed rules with particular examples. Behavioral and legal scholarship each present conflicting views about the optimal degree of specificity with which laws should be designed. From a behavioral standpoint, specificity is important to help people understand their goals and use their cognitive resources in a focused manner. At the same time, ambiguity in the law can even encourage good people to engage in creative interpretations of legal requirements, allowing them to justify unethical behavior, with limited awareness of the meaning of that behavior. By contrast, theories of crowding out, trust, and cooperation suggest that specificity can create resentment and lead to under-compliance and under-performance. These conflicting views about the effects of specificity serve as the background for this experimental project. This paper studies the effects of specificity on behavior in response to a directive that shares important features with the law. First, we examine the effect of specificity on compliance (following a directive) versus performance (beyond a minimum threshold). Second, we compare the controlling, limiting effects of specificity with its instructive, informative effects by comparing the interaction between specificity and monitoring with the interaction between specificity and good faith. We hypothesized that the combination of specificity and monitoring enhances the effect of specificity on compliance but harms performance and trust, whereas the combination of specificity and good faith enhances both the informative goal-setting aspects of specificity and people's sense of commitment. The study employs an experimental design in which subjects edit a document after being exposed to detailed (vague) instructions, with (without) a reference to good faith, and with (without) monitoring (through sanctioning). The assignments were designed in such a way that people could engage in various levels of editing (both required and not required, reasonable and more than reasonable), allowing us to measure distinctly both compliance and performance. Our results suggest that when participants require information and guidance, as in the case of editing a document, specificity increases performance even beyond what is required relative to a vague standard condition.

\footnotetext{
*For helpful comments, the authors are grateful to Tami Kricheli-Katz, Maya Bar-Hillel, and participants at the Eighth Annual Conference on Empirical Legal Studies at the University of Pennsylvania, the 24th Annual Meeting of the American Law and Economics Association at the University of Chicago, the Second Meeting of the Private Law Consortium at the University of Pennsylvania, the 2013 American Law and Society Association Meeting, the behavioral law faculty workshop of the IDC, HUJI, and TAU. For excellent research assistance, we would like to thank Troy Schuller, Einav Tamir, and Justin Zelin. For funding with thank the Edmond J. Safra Center for the Study of Ethics at Harvard University and the support of the Israeli Science Foundation (grant 1283/11).
} 


\section{Introduction}

The optimal specificity of directives is one of the most basic questions in law. Most theoretical lines of research have addressed the level of discretion that should be given to adjudicators as well as to lay people who need to comply with the law. This paper will focus on the impact of specificity on the meaning of the law and on individual-level decision-making. We will examine whether the trade-off between specificity and uncertainty postulated by classical law and economics perspectives undergoes significant changes if we combine the behavioral and rational choice accounts of specificity.

The rational choice and behavioral literatures contain a web of conflicting theories about how specific a law ought to be for it to have an optimal effect. Specificity can create a trade-off between treating individuals strictly, which ensures that minimum thresholds are met, and allowing them greater discretion, which can generate goodwill, possibly resulting in higher overall performance. In a related vein, the literature has considered what level of monitoring optimizes compliance, and when intrinsic motivation is better than monitoring at promoting compliance (Garoupa, 1997, 2003). Building these subtleties into the language of the law adds yet another level of complexity to the issue.

The theoretical literature on rational choice (e.g., multi-task agency, measurement paradoxes) and behavioral issues (e.g., crowding out, justice motivation, goal setting, and resentment) has made numerous competing predictions about how these various forces interact (which we review below). Further complicating our ability to create straightforward predictions are the distinct and disparate effects of ambiguity predicted by the rational choice and behavioral literatures. For example, whereas the rational choice literature claims that ambiguity can lead to a chilling effect, the behavioral literature predicts that ambiguity can lead to under-compliance owing to self-deception (about one's own compliance).

Recognizing that the theoretical bases for the effects of specificity are complex, we seek to understand which is more important for the law: the effect of specificity on compliance or its effect on performance? The management literature has suggested various answers to this question in the context of organizations. We wish to extend this question to the law, where in certain contexts specificity can be helpful in encouraging individuals to follow the letter of the law (compliance), but it may be harmful when we want individuals to follow the spirit of the law (performance).

The paper offers a richer behavioral account for specificity in law, which will be sensitive to the different functions of specificity and to the motivational mode of the individual. It is our belief that some of the conflicting views in the literature are related to an over inclusive treatment of sensitivity and to a limited account of the interaction between the cognitive and motivational accounts of specificity. Hence, to achieve a more realistic understanding of the contexts in which specificity may affect behavior, we attempt to understand its effect on the two main normative approaches, monitoring and deterrence on the one hand, and good faith and 
morality on the other. Based on the current literature, the combination of these two motivational aspects captures much of the relevant variation in the direction of the effect of legal specificity on compliance and performance.

The paper proceeds as follows. In Part 2 of the paper, we show that the question of optimal level of details in law is of importance for several legal doctrines. We review some of the main paradigms in this field and highlight some open areas that can be investigated empirically.

Next, we suggest that some of the reasons this question is still open in law is related to the even greater inconsistency that exists both in the rational choice and the behavioral literature. We review and compare some of the leading theories about how people are expected to respond to specific versus vague instructions. The core of our argument has to do with the interaction between specificity and motivations for compliance. We also review the literature on intrinsicextrinsic motivation, enforcement approaches, and the effect of measurement on behavior. Based on this review, we suggest some competing predictions about the possible effects of these three foactors, individually and together.

We proceed in Part 3 to present the empirical research questions and the unique methodological design that we use to gauge the effects of specificity on behavior. We explain why the context of language enables us to compare the effect of editing instructions on a narrow notion of compliance (doing what's required) with a broad notion of compliance (fixing errors which were not present in the specific instructions) as well as of a third category of errors which required extra effort or beyond reasonable compliance, which we call performance (e.g. content related fixes) ${ }^{1}$.

To create an empirical paradigm, which will allow for a comparison between the two types of behaviors we are after - compliance and performance - we have focused on a specific genre of legal specificity, which we refer to as example giving. While people might usually refer to driving 55 miles per hour as the classical prototype of specificity, we believe the dilemma of whether regulators should provide laws with detailed examples as to the meaning of the law is highly important for many legal doctrines. Part of this type of specificity has recently received an analytical treatment by Parchomovsky and Stein (2014) who define example giving as a "catalog" approach. According to their approach, which focuses mainly on the interaction between the legislative branch and the judicial branch, in many areas of law there is a middle hybrid approach that employs vague standards on one hand and detailed examples on the other hand, which is

\footnotetext{
${ }^{1}$ Please note that we are examining also the effect of specificity on compliance and performance in a different context, where people need to evaluate their own behavior, as representing the situation of a sale of a product. The results for this experiment will be reported in a different study that focuses on the interaction between legal specificity and ethical decision making.
} 
aimed at helping people understand the rationale of the specific law. ${ }^{2}$ Indeed, in reality, the situation is even broader: specific laws or contracts do not provide any general standard regarding the overall purpose of the law or contract in addition to the specific instructions. Hence, we believe that accounting for this type of legal specificity carries importance for numerous private law doctrines as well as many types of commercial contracts. ${ }^{3}$

Following a presentation of the findings of the study on the effect of example giving on compliance and behavior under conditions of either good-faith or monitoring, in Part 4 we examine the implications of the findings for the legal context in which some level of specificity needs to be chosen and we elaborate on the limitations of the study.

\section{Existing Approaches to Specificity}

\subsection{Accounts of Specificity in Law and Economics}

In legal scholarship, much of the debate on the optimal specificity of law comes from the "rules versus standards" paradigm, where standards are vaguer than rules. Kaplow's (1992) seminal paper on this topic and many follow-up studies have translated the notion of "optimal specificity" into "optimization of information costs." Kaplow includes various costs and benefits of rules versus standards in his model, but broadly speaking, rules are more costly to create but cheaper to enforce.

Some economic analyses point to the benefits of vagueness, but these benefits are often the flip side of costs. Thus, vagueness can smooth out the liability function, which may reduce the cost of errors in selecting the point at which the sanction sets in (Cooter 1984; Craswell and Calfee 1986). Contracting parties often include vague terms in their contracts, which can serve as a commitment device that increases the cost of litigation (Choi and Triantis 2010). An additional perspective comes from the multi-tasking paradigm that focuses on the problems that occur when some aspects of someone's own work are easier to monitor than others. According to the rational choice prediction, the agent focuses most of her work on the tasks for which she can be given an incentive (Holmstrom and Milgrom 1991).

An additional line of research in law and economics focuses on the chilling effect, a form of over-compliance. Ferguson and Peters (2000) argue that "the optimal amount of vagueness in a rule strikes a balance between the costs of loopholes, the chilling effect on economic activity, and the inefficiency created in the legal system." Economic analyses focus on how risk-neutral agents might over-comply with a vague law if the law is built around the

\footnotetext{
${ }^{2}$ The following example of a catalog is offered on p. 21 of their paper regarding the meaning of prohibited dangerous weapons: "any pistol or other firearm (or imitation thereof) or other dangerous or deadly weapon (including a sawed-off shotgun, shotgun, machinegun, rifle, dirk, bowie knife, butcher knife, switchblade knife, razor, blackjack, billy, or metallic or other false knuckles).” D.C. St. § 22-4502 (2013). 
optimal standard, albeit vaguely. For example, Kyle Logue (2007) and others have noted that risk-averse taxpayers would over-comply with an uncertain legal rule coupled with high penalties. Calfee and Craswell (1986) showed that risk-neutral agents would be subject to two behavioral effects of legal uncertainty: uncertainty would reduce deterrence because of the prospect of escaping liability wrongfully (a false negative), but in a variety of contexts, this effect would be dominated by a tendency toward over-compliance, which has been recognized, for example, in tax law. Under a vague standard, uncertainty can cause damages to rise more quickly than social harm around the optimal point, leading the actor to reduce the expected liability by inefficiently over-complying.

\subsection{The Behavioral Perspective}

From a behavioral perspective, compliance with rules that do and do not include detailed examples, is not solely a matter of decision under risk, but rather, it encompass a whole array of cognitive (e.g., attention, information) and motivational (e.g. resentment, trust and commitment) factors. Hence, the behavioral account of specificity supplements the rational choice perspective in a few ways: it provides a richer and more nuanced view of the different functions served by specificity and, in addition, it enables a better understanding of the interaction between specificity and the motivation people have toward the behavior. Our study demonstrates that, by taking this nuanced approach to specificity, we can improve the predictability of the effect of specificity on behavior in different contexts.

On the motivational side, behavioral research focuses on aspects such as work morale and resentment that may lead subjects to view specificity and over-detailed rules as a sign of mistrust and as a signal to extrinsic rather than intrinsic motivation (i.e. crowding out). On the positive side, the literature on motivated reasoning and self-concept maintenance, specificity might reduce the option for self-serving biases. The cognitive literature also points in multiple directions. In a negative cognitive effect, specificity causes subjects to pay too much attention to detailed instructions and to succumb to an availability bias, leading to unintended ignorance of other unspecified aspects. In contrast, on the positive cognitive side of specificity, literature such as that on goal-setting suggests that specificity may increase work focus better than "do your best."

An additional way in which the behavioral literature contributes to the rational choice discussion is by emphasizing the distinction between compliance and performance. Elsewhere we have demonstrated the importance of this dichotomy for legal theory (see Feldman and Smith, 2014). While in compliance we focus on people doing exactly as required, in performance we measure whether people making an extra effort to fulfil the spirit of the request (see Garcia et al 2014). There are also various intermediate level of behaviors, which the literature sometimes terms "beyond compliance" or extra role behavior (see e.g. Kim and Mauborgne 1996).

In the following paragraphs, we develop these conflicting views in the literature in a clearer and more analytical way. 


\subsubsection{Behavioral Advantages of Specificity}

The main psychological theory that challenges the negative views of specificity in the behavioral literature is 'goal setting'. The theory, which is highly influential in the management literature, claims (and data have shown) that challenging goals lead to higher performance than vague ones, such as "do your best." For example, Locke et al. (1987) reported 24 field experiments that found that individuals with specific, challenging goals either outperformed others or outperformed their own past performance when they had been instructed to simply "do their best." Latham and Yukl (1975) reviewed earlier studies of performance and similarly concluded that when people are given specific, complex goals they perform better than when being asked to simply "do their best." A classic study conducted by Seijts and Latham (2001) compared giving people "do your best" instructions versus assigning distal and proximal goals, and found that the combination of goals led to better performance than did the "do your best" approach. However, the "do your best" approach produced better performance than did the assignment of distal goals only. Therefore, this line of research seems to suggest that when specificity helps provide clear instructions and when it increases feelings of self-efficacy it is superior to ambiguous standards or instructions. However, it should be noted that even the goalsetting paradigm recognizes contexts in which specific instructions can cause underperformance compared with ambiguous ones. For example, Zhou and Shalley (2004) have argued that "it is possible that goals that direct individuals' attention toward completing more task units would simultaneously direct their attention away from coming up with creative ideas about their work."

As suggested earlier, when considering the behavioral advantages of specificity, we must account not only for the cognitive but also motivational effects. Indeed, behavioral research, particularly in behavioral ethics, has found a correlation between a preference for ambiguity and a desire to justify one's questionable behavior. Haisley and Weber (2010), for example, found that people prefer ambiguous risks when such ambiguity allows them to justify their unfair behaviors, and Dana et al. (2007) found that people are less generous in situations in which they can appeal to moral ambiguity to explain their selfish behaviors. Similarly, Hsee (1995) found evidence that people make choices that satisfy their own preferences at the cost of not completing an assigned goal if they can exploit existing ambiguity about what decision could be considered to achieve the assigned goal (see also Ayal and Gino 2011).

Proposition 1A: Based on theories of goal setting and self deception, we propose that specificity will increase the likelihood of compliance with specific legal instructions, at least in a narrow sense, relative to an ambiguous instruction that doesn't provide any specific example.

\subsubsection{Behavioral Disadvantages of Specificity}

The jumping off point for the behavioral literature is the rational choice literature on how various methods of providing incentives will effect compliance through measurement, monitoring, and sorting. For example, a classic study by Lazear (2000) shows that the piece-rate approach, in which people are evaluated based on how many units they produce, results in higher 
performance than a fixed wage approach. These studies also argue that employees react only to measurable metrics, especially in situations where it is difficult to determine who does what. By contrast, aspects of the work that are not easily measured suffer from poor performance. In the measurement paradox and the related multi-tasking effects problem (Holmstrom and Milgrom 1991, Prendergast 1999), over time the accuracy of measurement decreases as people concentrate their effort strictly on the measured components of an activity, resulting in a decline in the overall quality of their performance. The behavioral literature likewise focuses on hard to measure dimensions of compliance and performance. Thus, people's intrinsic motivation to perform well is crowded out by the relationship between performance, measurement, and payment (Bowles, 2008).Therefore, specificity combined with monitoring that focuses only on given measurable components (the letter of the law) seems to produce a straightforward effect of crowding out intrinsic motivation and decreasing overall performance.

Chou et al. (2011) have recently applied this concept to the area of contract specificity and have shown how feelings of distrust, triggered by an overly specific contract, can lead people to low performance in a long-term contract and serve as an obstacle between the two sides in long-term relationships. The authors rely on a long list of negative psychological mechanisms, mostly related to motivation, which could be triggered when the parties create a contract. Here the overall prediction is that, with a less specific contract, employees will exert greater effect, strive for greater efficiency, and act in a more trustworthy way. The authors support these theoretical predictions with a series of experiments in which participants who were given a highly specific contract were less likely to perform well relative to those who were given a less specific contract. For example, the authors compared the effect of "notify within one hour" with that of "notify as soon as possible" as part of a comparison between specific and less specific contract terms. The specific term -- "within an hour" - is not just clear and informative; it is also framed in a way which completely limits one's choice, especially relative to what has been defined as a less specified condition - "as soon as possible" - which is not just flexible but also gives the other party a very strong signal of respect. We employ a different approach in this paper to examine the effect of specific rules. We do not constrain people's choices, but rather, we add some detailed examples to the vague standard (see Parchomovsky and Stein 2014).

Possibly the most advanced line of research involving the inadvertent cognitive effects of specificity concerns the debate around the efficacy of using checklists to ensure compliance (Gibbons and Henderson 2013). Most of the literature deals with the checklist as a way tof reducing human errors, especially in aviation and hospitals, by helping the staff maintain selfcontrol in stressful situations. The checklist has gained its fame mainly in the cockpit, where pilots found their routine missions too long and complex to remember. Although the efficiency of the checklist is not contested anymore, the way to use and build checklists is still debated. Using a checklist on a daily basis can result in overuse, leading to low performance by making tasks automatic. Depending on its nature, a checklist can impair quality, reduce the expediency of services, and interfere with professional judgment and objective decision-making. 
Proposition 1B: Based on theories of crowding out, resentment and deviation of attention, we propose that specificity will reduce the likelihood that people engage in a broad sense of compliance (less easily measured margins) as well as performance.

\subsection{The Relationship between Specificity and Intrinsic/Extrinsic Motivation}

As hinted above, a possible way to better understand the relationship between the cognitive and motivational effects of specificity on both compliance and performance is related to its interaction with the motivational modes of those processing the language of the legal instrument. Many of the conflicting studies discussed above, for and against increasing the level of specificity of legal standards, fail to account for the role of motivation in a systematic way.

\subsubsection{The Importance of Intrinsic Motivation}

Research on why people obey the law starting with that of Tom Tyler (1990, 2006) demonstrates the importance of non-instrumental motivation, such as individuals' desire for fairness, in accounting for compliance and performance. Robert Frank (1988) recognized moral motivation as a force that encourages people to defy narrow versions of rational choice theory, making decisions that are either neutral or contrary to material self-interest. Much of the original behavioral economics literature examined how concepts of fairness may be employed to encourage individuals to overcome their own self-interest (see also Shavell, 2002). More broadly, economists argue that the law can cultivate social norms, which in turn serve as intrinsic motivation for compliance with the law (Cooter 2000). Cooter's work demonstrates the growing recognition among law and economics scholars in the superiority of compliance triggered by intrinsic motivation, due to the lack of reliance on monitoring, enforcement and stability (see also Feldman, 2011 for a review)

\subsubsection{Interplay between Specificity, Monitoring and Compliance Motivation}

From a policy-making perspective, the relevant question is not merely whether intrinsic motivation can increase compliance or performance, but whether and when does intrinsic motivation outperform extrinsic motivation in securing desirable behavior. In contexts in which intrinsic motivation is more successful in securing compliance, policy makers must make sure that the standard extrinsic motivators provided by law (e.g., sanctions and incentives) do not undercut intrinsic motivations. This issue has received attention mostly in the literature on crowding-out effects. We review some of the findings of this research, including its shortcomings, and then examine the conflicting literature that supports the idea that extrinsic motivation can serve to increase intrinsic motivation.

As noted earlier, extrinsic motivation is generally thought to undermine intrinsic motivation. Fehr (2002) argued that when people attribute their behavior to external rewards, they discount their moral incentives for their behavior, thereby lowering the apparent effect of intrinsic motivation. For example, paying people to donate blood causes donors to view the 
donation as a transaction rather than a charitable act, eroding altruistic blood donations. Similarly, in a series of lab-based experiments, Deci (1971) found that tangible rewards undermine intrinsic motivation for a range of activities. In another study Deci et al. (1999) argued that "tangible rewards tend to have a substantially negative effect on intrinsic motivation." In a similar vein, Marshall and Harrison's (2005) work suggests that the use of incentives can damage self-esteem, resulting in the perception that professionalism is no longer valued.

Yet another nuance of this theory suggests that the effect of incentives is not linear, but rather that "intermediate" payouts have a disproportionately high crowding-out effect compared with low or high payout levels. Tenbrunsel and Messick (1999) argued that a weak system of sanctions produces worse results than having no sanctions at all. By introducing a sanctioning system, the principal changes the evaluation of the problem from an ethical dilemma to a business decision, consequently shifting individual considerations away from ethics and toward self-interest. ${ }^{4}$

In contrast to the above research, some scholars in the accounting literature suggest that, over time, a control system and sanctions can increase the level of cooperation among partners and increase long-term trust ( Coletti, Sedatole, \& Towry, 2005) These possible influences raise concerns about whether such effects would be manifested also in the context of law. Work by Feldman and Tyler (2012) offers initial support for the suggestion that imposing a law on an existing social practice would enhance, rather than undermine, the effectiveness of the social practice.

Specificity may also affect the relationship between agent and principal, making the agent resentful toward the principal owing to fear or lack of trust. Lack of trust may be another route by which specificity decreases intrinsic motivation and the resulting performance on a given task. We already noted that a series of studies by Chou et al. (2011) examines how people perceive specific contracts, and their results suggest that specificity crowds out intrinsic motivation through perceptions of mistrust [see also results by Fehr and Gächter (2000)]. This conclusion is also supported by an earlier study by Messick and Tenbrunsel (1999), who argued more broadly that strict enforcement, sanctions, and specificity can harm cooperation. Dickenson and Villeval (2008) maintained that when principals engage in costly monitoring, agents react to the resulting discipline of monitoring by increasing effort. However, they also reported that intrinsic motivation is crowded out when monitoring exceeds a certain threshold. Overall, they

\footnotetext{
${ }^{4}$ One caveat is that in many cases external rewards can enhance intrinsic motivation. The interpersonal context in which the extrinsic motivation is introduced, or even the verbal cues attached to the sanctions, can determine how much we intrinsically value the extrinsic reward. For example, a child being reprimanded by a parent, whose opinion the child greatly values, may experience an greater increase in motivation to behave well than if the same reprimand were issued by a teacher with whom the child has little rapport. Nevertheless, the consensus in the literature suggests that in most instances attempts to externally control people's behavior can have considerable counterproductive results in the long term. (For a review of some of these conflicting effects, see Deci et al. (2001).
} 
tend to agree with the views of Osterloh and Frey (2013) that "A job providing decision latitude enhances employees' self-determination and thereby strengthens interest and pride in the job." Their overall conclusion is that monitoring negatively affects the principal-agent relationship rather than crowding out intrinsic motivation.

A similar view is supported by the work of Falk and Kosfeld (2006), who demonstrated the effect of specificity on the principal-agent relationship in experiments in which the principal could either let an agent decide a production amount (ambiguous instruction) or the principal could set a lower limit for production (specific instruction). When a specific lower limit was set, agents produced less than when the principal left the production levels to the agent's discretion. In post hoc questioning, agents stated that they saw the specific lower limit as a signal of distrust and therefore behaved less cooperatively. Specific instructions also give individuals less room for discretion, creating a situation in which the individual must constantly look for external instructions.

Proposition 2A: Based on the research on crowding out and signals of mistrust, a combination of specificity with high external controls will increase compliance but will reduce performance.

Proposition 2B: Along the same lines, a combination of specificity with focus on morality and good faith will mitigate the negative motivational aspects of specificity and will increase both compliance and performance.

\section{Experimental Method}

To determine how to bring together the approaches to the optimal level of specificity, in the next section we explore the effect of specificity experimentally, in a way that allows for a comprehensive examination of competing theories about how specificity affects both compliance and performance. Below we explain the methodological approach we follow in the present paper to further our understanding of how the type of specificity employed in the law interacts with some of the main relevant enforcement mechanisms related to intrinsic and extrinsic motivation: monitoring and good faith.

The combination of specificity, monitoring, and good faith in a 2x2x2 design, using a variety of incentive-compatible behaviors and psychological measures as dependent variables, enables us to explore a spectrum of effects of legal specificity across a range of contexts. Understanding how specificity affects each dimension, both alone and in tandem with monitoring and a good faith requirement, allows us to develop a coherent understanding of how to optimize the language of the law in order to encourage compliance and performance. Furthermore, the behavioral dependent variable chosen for this project is language editing, which gives us the freedom to vary the level of specificity. Although we assume that most participants have some notion of what editing means, the task of editing still makes it possible to emphasize some aspects in greater detail without undermining the overall meaning of the activity. It is also an area in which some objective criteria for evaluation exist, but levels of performance can vary, 
permitting us to determine the extent to which participants were merely doing the minimum or trying their best.

\subsection{Design}

In the study, we explore the relationship between specificity, good faith, and monitoring on compliance and performance. Specifically, we seek to determine the effect of contract-style specificity - by adding detailed examples to only half of the participants - on editing effort. As suggested above, while we are interested in understanding the effect of increasing or decreasing specificity on people's compliance and performance, we are not comparing the two extreme conditions as some of the other studies on specificity have suggested (Chou et al. 2010), but rather the effect of a general instruction versus a condition where we add some specific examples (out of many other categories) of what the vague standard means.

We operationalize compliance and performance as the number of attempted corrections of a text document that contains nine (9) types of errors: verb tense, punctuation, subject-verb agreement, missing words, word meaning, pronoun usage, article usage, singular/plural, and apostrophe usage. There were a total of 54 mistakes in the 1,592-word document that was distributed for editing. The experiment was conducted online in October 2012, with a sample of 339 respondents who were recruited from Amazon Mechanical Turk, a crowd-sourcing Internet labor market. Respondents were paid $\$ 1.50$ for participating in the study $(58 \%$ female; mean age $=32.48, \mathrm{SD}=11.23)$.

Respondents were first shown a page with information about the study and a statement of informed consent. After a respondent opted into the study, he or she was then randomly assigned to one of eight experimental conditions that primed respondents with different combinations of specificity, good faith, and monitoring $(2 \times 2 \times 2)$. Below is an overview of the treatment manipulations.

\section{Specificity Manipulation:}

Respondents who were exposed to the specificity condition were informed that the editing task contained, among others, punctuation and verb tense sequencing errors. Respondents were provided with examples of proper punctuation and verb tense usage, which was followed by a short multiple-choice quiz. Those who were not assigned to the specificity condition (ambiguous condition) received no such information. The specificity manipulation was intended to highlight a subset of specific types of errors, while also reminding the respondent that there were other error types not mentioned. The expectation was that participants who were given instructions with specific error type examples would focus more on these "mentioned" examples of error types when correcting the document. The seven error types not mentioned were either grammatical, which require a "reasonable" amount of attention to detect, or content-related, which require a "more than reasonable" level of focus. We expect that the specificity condition 
should increase the level of editing of the mentioned error types and reduce editing performance for non-mentioned types of errors.

\section{Good Faith Manipulation:}

Participants assigned to the good faith treatment were instructed that they were to act in good faith while editing the text document, meaning that the editor should act in a genuine, sincere, fair, and honest manner while participating in the study. Furthermore, those in the good faith condition were also asked to write a couple of sentences on what good faith means to them, as well as what it means to edit a document in good faith.

Respondents with specific instructions and who are assigned to the good faith conditions should be less likely to abandon non-mentioned error types.

\section{Monitoring Manipulation:}

Those assigned to the monitoring condition were instructed that satisfactory execution of the editing instructions would lead to a reward of a bonus payment of $\$ 1.00$, and that, before making this payment, study administrators would carefully review the respondent's performance and how closely he or she followed the instructions of the study. Moreover, respondents in the monitoring condition were asked to estimate the number of minutes they believed the researchers would invest in verifying that the instructions were followed satisfactorily before payment of the bonus. Participants with specific instructions in the monitoring condition should be more likely to edit only what is required (mentioned error types).

\section{Dependent Variable:}

Summarizing the dependent variable employed in this study, we operationalize compliance and performance with the number of attempted copy editing corrections over nine distinct types of errors. Due to the nature of how the specificity treatment was framed, we can classify these error types into three categories of compliance and performance: narrow compliance, broad compliance, and performance. Respondents who were given specific instructions were informed of the presence of two types of errors (punctuation and verb-tense). As discussed above, we would expect that a minimal level of compliance with the instructions would involve editing these explicitly mentioned error types. The unmentioned error types fall under two categories. The first are grammatical errors that objectively require low levels of effort in order to detect, such as singular/plural mistakes. Respondents given specific instructions and who edited these types of errors displayed broad compliance: effort which goes beyond the explicit instructions but which is simultaneously objectively easier to monitor. The second category of unmentioned error types encompasses the notion of performance. These content-related errors, such as word meaning, require a closer reading of the text and, as such, detection of these errors signals that the respondent went "above and beyond" the explicit instructions provided. 


\subsection{Methodology}

Because we assigned individuals randomly to the various treatment conditions, we made the concepts of monitoring, good faith, and specificity salient before the participants completed the editing task. Thus, we were able to directly compare whether the number of corrected errors differed across these conditions. The data were analyzed using a three-factor analysis of variance (ANOVA) model, with the specificity, good faith, and monitoring treatment conditions as the factors. As there was only one error in the categories of article usage, singular/plural, and apostrophe usage, we used logistic regression to estimate the effects of the experimental conditions. A statistically significant positive $(\mathrm{p}<0.01)$ main effect of specificity on post-treatment English knowledge performance led us to also include knowledge of English as a control in all models of the study.

Following exposure to the various treatment manipulations, respondents were asked to edit a 1,592-word document for errors in 15 minutes. Depending on the conditions to which participants were assigned, a reminder of the condition was shown above the document. Those in the good faith category were again told that they were expected to act in good faith while editing the text document according to the instructions. Participants exposed to the monitoring treatment were reminded of the bonus payment, its contingency on compliance with the instructions, and that their performance would be evaluated by the researchers. Likewise, respondents in the specificity category were reminded that the document contained punctuation and verb tense errors, among others.

To minimize measurement error and also economize resources, we use an automated approach to evaluate editing effort. Respondent editing performance was measured using an algorithm, which employs a set of regular expressions, that searches each edited document, finds and flags all the instances in which a change has been made to incorrect text, and tallies the number of attempted corrections made by the respondent for each type of error (e.g., punctuation, verb tense, subject-verb agreement, etc.). Note that in our study, performance refers to the number of attempted corrections made by the participant. Since we are interested in effort, we are not concerned with editing accuracy, but rather whether an editing attempt was made.

\subsection{Results}

With regard to main effects, results suggest that the specificity treatment had great importance in increasing performance. As shown in Table 1, we found that respondents exposed to the specificity treatment corrected more verb tense errors $(\mathrm{M}=4.945, \mathrm{SE}=$ $0.236)$ than those in the ambiguous treatment $(\mathrm{M}=3.90, \mathrm{SE}=0.248), \mathrm{F}(1,330)=9.211$, $\mathrm{p}<0.01 .^{5}$ This result conforms to our theoretical expectation that respondents in the specificity treatment condition would correct significantly more "mentioned" error types.

\footnotetext{
${ }^{5}$ To demonstrate the validity of our measurement of task performance, namely, the number of attempted corrections made by the respondent, we calculate the correlation between time spent on the editing task and
} 
Table 1: Three-way Analysis of Variance for Verb Tense Attempted Corrections

\begin{tabular}{llllll} 
& Partial SS & df & MS & F & p-value \\
\hline Model & 383.430 & 8 & 47.929 & 5.000 & 0.000 \\
Monitoring & 0.075 & 1 & 0.075 & 0.008 & 0.930 \\
Good Faith & 0.001 & 1 & 0.001 & 0.000 & 0.992 \\
Monitoring ${ }^{*}$ Good Faith & 13.101 & 1 & 13.101 & 1.367 & 0.243 \\
Specificity & 88.306 & 1 & 88.306 & 9.211 & 0.003 \\
Monitoring Specificity & 0.080 & 1 & 0.080 & 0.008 & 0.927 \\
Good Faith*Specificity & 2.771 & 1 & 2.771 & 0.289 & 0.591 \\
Monitoring*Good Faith ${ }^{\star}$ Specificity & 7.870 & 1 & 7.870 & 0.821 & 0.366 \\
English & 215.171 & 1 & 215.171 & 22.445 & 0.000 \\
Residual & 3163.549 & 330 & 9.587 & &
\end{tabular}

But we also found significant main effects of the specificity treatment on other error types, not mentioned in the treatment prompt. Table 2 displays the results of the analysis of subject-verb agreement attempted correction. We found a statistically significant and positive effect, $\mathrm{F}(1,330)=11.684, \mathrm{p}<0.001$, of specificity on the level of subject-verb agreement corrections, with the specificity group showing a higher $(\mathrm{M}=7.095, \mathrm{SE}=$ $0.253)$ number of corrections than those without it $(\mathrm{M}=5.832, \mathrm{SE}=0.266)$.

Table 2: Three-way Analysis of Variance for Subject-Verb Attempted Corrections

\begin{tabular}{llllll} 
& Partial SS & df & MS & F & p-value \\
\hline Model & 543.592 & 8 & 67.949 & 6.169 & 0.000 \\
Monitoring & 16.366 & 1 & 16.366 & 1.486 & 0.224 \\
Good Faith & 0.906 & 1 & 0.906 & 0.082 & 0.774 \\
Monitoring*Good Faith & 2.308 & 1 & 2.308 & 0.209 & 0.647 \\
Specificity & 128.703 & 1 & 128.703 & 11.684 & 0.001 \\
Monitoring $^{*}$ Specificity & 0.011 & 1 & 0.011 & 0.001 & 0.975 \\
Good FaithSpecificity & 0.052 & 1 & 0.052 & 0.005 & 0.945 \\
Monitoring*Good Faith ${ }^{*}$ Specificity & 15.042 & 1 & 15.042 & 1.366 & 0.243 \\
English & 283.956 & 1 & 283.956 & 25.778 & 0.000 \\
Residual & 3635.069 & 330 & 11.015 & &
\end{tabular}

The results of the analysis of the number of attempted corrections for missing words are shown in Table 3. We found two statistically significant main effects. First, we found that respondents exposed to the monitoring treatment made fewer corrections $(\mathrm{M}=2.391$, $\mathrm{SE}=0.152)$ than those without the monitoring condition $(\mathrm{M}=2.883, \mathrm{SE}=0.157), \mathrm{F}(1$,

the percentage of total errors which were attempted to be corrected. We find a correlation coefficient of 0.43 , indicating a moderately strong positive correlation between time and performance; suggesting that the focus on attempted corrections was the right one. 
$330)=5.103, p<0.05$. Second, respondents in the specificity treatment group made more missing words corrections $(\mathrm{M}=2.855, \mathrm{SE}=0.151)$ than those exposed to ambiguous instructions $(\mathrm{M}=2.419, \mathrm{SE}=0.159), \mathrm{F}(1,330)=3.894, \mathrm{p}<0.05$.

Table 3: Three-way Analysis of Variance for Missing Words Attempted Corrections

\begin{tabular}{llllll} 
& Partial SS & df & MS & F & p-value \\
\hline Model & 123.573 & 8 & 15.447 & 3.927 & 0.000 \\
Monitoring & 20.074 & 1 & 20.074 & 5.103 & 0.025 \\
Good Faith & 0.037 & 1 & 0.037 & 0.009 & 0.923 \\
Monitoring ${ }^{*}$ Good Faith & 12.295 & 1 & 12.295 & 3.125 & 0.078 \\
Specificity & 15.317 & 1 & 15.317 & 3.894 & 0.049 \\
Monitoring $^{*}$ Specificity & 3.571 & 1 & 3.571 & 0.908 & 0.341 \\
Good FaithSpecificity & 4.887 & 1 & 4.887 & 1.242 & 0.266 \\
Monitoring*Good Faith ${ }^{\star}$ Specificity & 3.035 & 1 & 3.035 & 0.772 & 0.380 \\
English & 49.834 & 1 & 49.834 & 12.669 & 0.000 \\
Residual & 1298.096 & 330 & 3.934 & &
\end{tabular}

Similarly, as illustrated in Table 4, we found a positive and statistically significant effect, $\mathrm{F}(1,330)=5.084, \mathrm{p}<0.05$, of specificity on the number of word meaning corrections: respondents presented with specific instructions had an average of $2.552(\mathrm{SE}=0.121)$ attempted corrections while those given ambiguous instructions prior to the editing task who had an average of $2.154(\mathrm{SE}=0.127)$ attempted corrections.

Table 4: Three-way Analysis of Variance for Word Meaning Attempted Corrections

\begin{tabular}{|c|c|c|c|c|c|}
\hline & Partial SS & $\mathrm{df}$ & MS & $F$ & $\mathrm{p}$-value \\
\hline Model & 80.520 & 8 & 10.065 & 3.998 & 0.000 \\
\hline Monitoring & 1.490 & 1 & 1.490 & 0.592 & 0.442 \\
\hline Good Faith & 1.100 & 1 & 1.100 & 0.437 & 0.509 \\
\hline Monitoring ${ }^{\star}$ Good Faith & 5.838 & 1 & 5.838 & 2.319 & 0.129 \\
\hline Specificity & 12.798 & 1 & 12.798 & 5.084 & 0.025 \\
\hline Monitoring*Specificity & 3.738 & 1 & 3.738 & 1.485 & 0.224 \\
\hline Good FaithSpecificity & 0.438 & 1 & 0.438 & 0.174 & 0.677 \\
\hline Monitoring ${ }^{*}$ Good Faith ${ }^{\star}$ Specificity & 0.357 & 1 & 0.357 & 0.142 & 0.707 \\
\hline English & 44.628 & 1 & 44.628 & 17.729 & 0.000 \\
\hline Residual & 830.707 & 330 & 2.517 & & \\
\hline
\end{tabular}

Thus, when it comes to non-required tasks as well as those that require extra attention, specificity didn't have a similar effect to that of monitoring and caused people to perform better in those tasks.

As shown in Table 5, the interaction of monitoring and specificity was statistically significant, $F(1,330)=4.478, p<0.05$, with respect to the number of 
punctuation error corrections. Respondents exposed to the specificity condition without monitoring performed better $(\mathrm{M}=5.215, \mathrm{SE}=0.229)$ than those assigned to the ambiguous treatment without monitoring $(M=4.481, \mathrm{SE}=0.256)$. Specificity produced no significant difference in performance among those in the monitoring condition. As with the main effects, this interaction result suggests that respondents may be reacting to the "mentioned" error types in the specificity treatment prompt.

Table 5: Three-way Analysis of Variance for Punctuation Attempted Corrections

\begin{tabular}{llllll} 
& Partial SS & df & MS & F & p-value \\
\hline Model & 237.660 & 8 & 29.708 & 6.298 & 0.000 \\
Monitoring & 1.448 & 1 & 1.448 & 0.307 & 0.580 \\
Good Faith & 2.044 & 1 & 2.044 & 0.433 & 0.511 \\
Monitoring ${ }^{*}$ Good Faith & 0.192 & 1 & 0.192 & 0.041 & 0.840 \\
Specificity & 4.217 & 1 & 4.217 & 0.894 & 0.345 \\
Monitoring ${ }^{*}$ Specificity & 21.122 & 1 & 21.122 & 4.478 & 0.035 \\
Good Faith $^{*}$ Specificity & 0.271 & 1 & 0.271 & 0.057 & 0.811 \\
Monitoring*Good Faith*Specificity & 1.548 & 1 & 1.548 & 0.328 & 0.567 \\
English & 195.069 & 1 & 195.069 & 41.352 & 0.000 \\
Residual & 1556.699 & 330 & 4.717 & &
\end{tabular}

We also found a significant interaction effect between monitoring and good faith at the $10 \%$ error level for the missing words model which is shown in Table 3. We found that respondents who were not exposed to the good faith treatment but were treated with the monitoring condition performed worse $(\mathrm{M}=2.209, \mathrm{SE}=0.201)$ than those who were neither in the good faith nor in the monitoring conditions $(\mathrm{M}=3.086, \mathrm{SE}=0.233)$. Monitoring had no significant effect on performance among the participants assigned to the good faith condition.

We found no statistically significant three-way interaction effect of the three treatments on the number of corrections for any error type.

The empirical results suggest a nuanced role of specificity on editing performance. In line with Proposition 1A, we find that respondents in the specificity condition, who were provided with a list of mentioned error categories, were more likely to attempt to correct these types of errors than respondents who were given ambiguous instructions. However, contrary to Proposition 1B, we also found that respondents in the specificity condition were also more likely to correct many of the unmentioned types of errors. The main effect results of specificity suggest that there is some type of spill-over effect, given that respondents with the specificity treatment not only performed better with respect to "mentioned" error types but also with respect to "unmentioned" error types. Of the "unmentioned" errors, we found a significant main effect on all content-related types (missing words and word meaning) as well as 1 of 5 grammatical types (subject-verb agreement). 
We attribute the spill-over effect to an increase in the level of attention and not necessarily to heightened intrinsic motivation. We believe that by offering examples of error types to these respondents, they became more careful and thus more likely to identify errors of all types. Respondents exposed to the specificity treatment were more likely to attempt to correct all of the content-related error types (high effort) and some grammatical-related types (lower effort). These results may reflect more of the instructional aspect of specificity than notions of morality/specificity. That is, for certain tasks, such as copy editing, the provision of specific instructions may not necessarily affect the intrinsic motivation of respondents. In certain contexts, specific instructions may indeed be sought after and welcomed by agents who otherwise would perceive the task as prohibitively ambiguous.

With respect to our theoretical expectations laid out in Propositions $2 \mathrm{~A}$ and $2 \mathrm{~B}$, we find little evidence. As a reminder, Proposition 2A states that the combination of specific instructions and monitoring would lead to increased compliance but reduced performance. Of the nine error types, we found a statistically significant interaction effect of these two conditions only for punctuation errors, which is an error type mentioned in the specific instructions. However, we found that among those given specific instructions, respondents who were not given a monitoring treatment did better at detecting punctuation errors than subjects who were given a monitoring treatment. To further illustrate the mixed results, we found no significant interaction effect for verbtense errors, which was the second error type mentioned in the specific instructions. With respect to Proposition $2 \mathrm{~B}$, that the combination of specific instructions and good faith should lead to higher levels of compliance and performance, our results could not find support for this proposition. The interaction term of these variables was not statistically significant at traditional levels across all error types.

\section{Discussion}

\subsection{The multiple facets of specificity}

Our findings dovetail with the complex literature review we have started the paper with, in showing that any attempt to portray specificity as either good or bad might derive from a partial view of specificity. In contrast to most of the current views of specificity which focus either on the informative value of specificity (e.g. Kaplow 1992; Sunstein 1995; Schlag 1985) or the motivational aspect of specificity (see, e.g., Chou et al. (2010) for a behavioral perspective, or Shiffrin (2010) for a philosophical one), our design has attempted to explore both the motivational and the informative functions of specificity, using one integrative design, featuring a few incentive compatible behavioral measures. Furthermore, we have taken a mild, realistic, and balanced approach, where we did not focus on the extreme high and low values of specificity but rather on the realistic hybrid version, in which vague legal standards are reinforced with some detailed examples. 
From our findings, we can begin to address what is the right approach to account for the different functions of legal specificity.

First, we have found that respondents who were given specific instructions related to the editing task were more likely to attempt to correct errors found in the document than those who were given ambiguous instructions. Furthermore, we have found that subjects who were given the specific instructions attempted significantly more corrections for error types which were mentioned in the instructions as well as for error types that were not mentioned.

Second, providing detailed examples might be needed both for informativeness and for motivation. Our findings seem to suggest that when specificity is providing useful information to participants, the motivational role of specificity is more indirect. We have found that those who were given specific instructions were much more likely to attempt corrections for many error types relative to those who were given ambiguous instructions.

In addition to the ability of specificity to contribute to people's compliance, our findings have shown that it even caused people to engage in better performance in areas beyond what was requested. On our interpretation, specificity can serve an informative function not only in the details it gives but also in its ability to help people focus on better performance, even in other categories of behavior.

When it comes to the ability of specificity design to help reduce the negative motivational effects which were shown in earlier studies on specificity, a few conclusions can be reached from our study. First, in contrast to the leading work of Chou et al. (2011), who argued that specificity increased resentment and consequently decreased performance, our study has shown that when specificity is phrased in an informative way, those resentful feelings are not triggered. Nevertheless, it still might be the case that when legal instructions are framed using highly constraining language, then the effect of specificity is indeed negative. Second, it is possible to use specificity using examples rather than a closed list and thereby avoid many of the problems associated with overfocusing and lack of flexibility. Third, if one is interested in optimizing specificity in contracts as well as in law and regulation, multiple factors need to be taken into account, such as the relative costs of over- and under-performance, the consequences of mistakes, the cost of monitoring and the information both the principal and the agent are expected to have about the task. Most of the answers to such questions require more focused empirical investigation and normative discussion which need to take place with regard to the specific doctrine in question.

\subsection{Good faith and Specificity}

Another important legal implication is related to the positive effect of good faith on people's interpretation of what is required from them. From our results, it seems that good faith was able to curb some of the failures associated with both specificity and monitoring. In particular, those exposed to the good faith treatment were less susceptible 
to the negative effect of monitoring. Given the previous results in the literature, our result suggests that an admonition for good faith may dispel distrust and resentment.

Naturally, there are other factors that should be taken into account such as the need for information, whether the examples used are such that might give the interpreter the correct signals regarding what might be other examples. The examples we used were from the core definitions of editing, but still people were interpreting the request for them to include even more remote examples of editing, including content-related mistakes which were planted in the text.

\subsection{Is there an Optimal Balance of Specificity, Good faith and Monitoring?}

In keeping with the exploratory nature of this study the conclusions we can draw for legal design are open-ended. Because law covers a wide variety of contexts - in which specificity will sometimes be informative and sometimes, in keeping with other literature, may signal distrust - attention to which context is which is a pressing necessity (see also Feldman and Smith 2014). Those of our findings that most closely examine the hybrid catalog approach to regulation suggest the advantage of this approach where participants were not constrained by the examples provided and also focused on fixing errors which were not mentioned. Hence, in that regard our findings corroborate the advantages of the catalog approach argued for by Parchomovsky and Stein (2014) as balancing the pros and cons of specificity.

The area that is probably closest to the editing task in our studies is contracts. The doctrine and the theoretical literature have long wavered on the benefits and costs of specificity and vagueness, both in contractual terms and off-the-rack rules (and standards). (See, e.g., Choi and Triantis 2008, 2010; Schwartz and Scott 1995.) More recently, experiments are being done to test the effect of specific goals for performance (see, e.g., Brooks, Stremitzer, and Tontrup 2013). At the same time, good faith is a much-discussed, non-waivable feature that law reads into contracts. The main criticism of good faith is that it lacks content (see, e.g., Miller and Perry 2012). The formulation employed in our studies keys off the contractual notion of good faith, and the effects we found suggest that, however difficult it may be to implement good faith as a legal rule, it is quite likely to have important effects on contractual performance, which after all is the point of contracts.

To make the problem of specificity, detailed regulation, good faith, and monitoring more tractable, further work will need to be conducted in order to find out exactly which parts of the context are most important. Also, theoretical and empirical work may suggest ways in which the law may address different audiences at different times: directives couched in terms of morality and good faith might be heard differently by those inclined to act ethically and those looking for loopholes to exploit (Feldman and Smith 2014). For now, one lesson to draw is that we cannot assume that specificity always crowds out intrinsic motivation or always ensures compliance - or always furnishes useful information to its addressees. 


\subsection{Limitations}

While suggestive, especially against the background of the previous literature, our study is subject to limitations that caution against overgeneralization.

Theoretically, as the introduction to the paper has hinted, there is a wealth of theories which bear relevance to the likely effect of specificity on behavior. Some of the theories, mainly from rational choice and management literature on goal setting, suggest that ambiguous instructions might cause people to underperform. Some of the other theories that focus on crowding out motivation and trust see specificity as a device which will cause people to underperform due to the harm to the sense of autonomy and intrinsic motivation (e.g. Shiffrin 2010). The real challenge for legal policy makers would be to identify ex ante the contexts in which specificity will increase or decrease performance.

In addition to the general theoretical point, there are some methodological points that we need to acknowledge. Somewhat surprisingly and in contrast to previous studies, we found a lack of a monitoring effect. We identify two main methodological reasons, which might limit our ability to generalize from this lack of effect. First, given that our subjects were mTurk participants, even in the non-monitoring condition, participants were already in a reputation market, especially in a task which allows the experimenter to harm their mTurk reputation - for failing to recognize the errors in the document. Second, IRB limitations with regard to payments to participants on mTurk have prevented us from threatening in a more serious way the payment to participants for failing to perform well. Focusing on the bonus payment allowed us some flexibility in "threatening" participants but this was a relatively limited threat and possibly not a credible one.

Another methodological limitation is related to the nature of copy-editing. Originally we viewed this as a relatively straightforward task, in which people might have a limited need to get actual examples and directions as to what might be considered as editing, especially at the core level. Our results suggest that participants have come to use these examples on the informational level to a greater extent than we anticipated. Furthermore, it is possible that editing meant a lot to some people and meant less to others, which might have moderated the effect of specificity. Where for some people, the specific instructions were helpful and informative and hence did not crowd out motivation, for others they were redundant and hence seemed to signal mistrust that might have created some motivational crowding out effect. While we have controlled for various factors, which capture level of knowledge of English, no such control can be perfect. Future research might need to examine the possible effect of specificity also in areas where participants already know about the task and the effect of specificity would be mainly to reduce people's discretion and to improve the ability of the principal to monitor the behavior of the agent. Having said that, we believe that our findings did help illuminate what we define as the multiple function of legal specificity in regulating behavior.

\section{Conclusion}


Specificity in directives of the kind employed by the law affects compliance and performance in context-sensitive ways, and our study is a first step in sorting them out. Contrary to arguments that specific instructions always crowd out motivation and harm performance, in our editing study we find that, when guidance may be needed, more specific instructions may lead to better performance (not only compliance). While the focus of this study was limited to a certain kind of specificity - a general rule with a list of examples - this experimental approach could be extended to other types of specificity and in other contexts of legal relevancy. Overall, our study suggests that, although quite difficult, it is worthwhile for legal designers to think carefully about how to calibrate the cognitive and motivational effects of specificity.

\section{References}

Ayal, Shahar and Francesca Gino. 2011. "Honest Rationales for Dishonest Behavior" in M. Mikulincer and P. R. Shaver (eds.), The Social Psychology of Morality: Exploring the Causes of Good and Evil, Washington, D.C.: American Psychological Association, 146-66.

Aquino, K., D. Freeman, A. Reed, W. Felpd, and V. K. Lim. 2009. "Testing a socialcognitive model of moral behavior: the interactive influence of situations and moral identity centrality," 97 Journal of personality and social psychology 123-41.

Barthélemy, Jérôme and \& Bertrand V. Quélin. 2006. "Complexity of Outsourcing Contracts and Ex Post Transaction Costs: An Empirical Investigation," 43 Journal of Management Studies 1775-97.

Bowles, Samuel. 2008. "Policies Designed for Self-Interested Citizens May Undermine 'The Moral Sentiments': Evidence from Economic Experiments," 320(5883) Science $1605-1609$.

Braithwaite, John. 2002. "Rules and Principles: A Theory of Legal Certainty," 27 Australian Journal of Legal Philosophy 47-82.

Brooks, Richard R. W., Alexander Stremitzer, and Stephan W. Tontrup 2013. "Stretch It But Don't Break It: The Hidden Risk of Contract Framing”. UCLA School of Law, Law-Econ Research Paper No. 13-22 (November 13, 2013). Available at SSRN: http://ssrn.com/abstract=2353733 or http://dx.doi.org/10.2139/ssrn.2353733.

Chapman, Bruce. 1995. "Corporate Tort Liability and the Problem of Overcompliance." 69 Southern California Law Review 1679-1703.

Choi, Albert and George Triantis. 2010. "Strategic Vagueness in Contract Design: The Case of Corporate Acquisitions," 119 Yale Law Journal 848-924. 
. 2008. "Completing Contracts in the Shadow of Costly Verification," 37

Journal of Legal Studies 503-34.

Chou, Eileen Y., Nir Halevy, and J. Keith Murnighan. 2010. "The Hidden Cost of Contracts on Relationships and Performance,", IACM 23rd Annual Conference Paper, available at SSRN: http://papers.ssrn.com/sol3/papers.cfm?abstract_id=1612376 (Date posted: May 21, 2010).

Cooter, Robert. 1984. "Prices and Sanctions," 84 Columbia Law Review 1523-60.

Craswell, Richard and John Calfee, John E. 1986. "Deterrence and Uncertain Legal Standards," 2 Journal of Law, Economics, and Organization 279-313.

Dana, Jason, Roberto A. Weber, and Jason Xi Kuang. 2007. "Exploiting moral wiggle room: experiments demonstrating an illusory preference for fairness," 33 Economic Theory 67-80.

Deci, Edward L. 1971. "Effects of externally mediated rewards on intrinsic motivation," 18 Journal of Personality and Social Psychology 105-15.

Deci, Edward L., Richard Koestner, R., and Richard M. Ryan. 1999. “A meta-analytic review of experiments examining the effects of extrinsic rewards on intrinsic motivation," 125 Psychological Bulletin 627-68.

Deci, Edward L., Richard Koestner, R., and Richard M. Ryan 2001. Extrinsic rewards and intrinsic motivation in education: Reconsidered once again. 71(1) Review of Educational Research 1-27.

Dickinson, David and Marie-Claire Villeval, M. C. 2008. "Does monitoring decrease work effort?: The complementarity between agency and crowding-out theories," 63 Games and Economic Behavior 56-76.

Falk, Armin and Michael Kosfeld. 2006. "The Hidden Costs of Control," 96 American Economic Review 1611-30.

Fehr, Ernst, \& Armin Falk. 2002. "Psychological foundations of incentives," 46 European Economic Review 687-724.

Fehr, Ernst and Simon Gächter. 2000. "Fairness and Retaliation: The Economics of Reciprocity," 14 Journal of Economic Perspectives 159-81.

Feldman, Yuval and Henry E. Smith. 2014. "Behavioral Equity," 170 Journal of Institutional and Theoretical Economics 137-59.

Feldman, Yuval and Tom R. 2012. "Mandated justice: The potential promise and possible pitfalls of mandating procedural justice in the workplace," 6 Regulation \& Governance 46-65. 
Ferguson, Michael F., and Stephen R. Peters. 2000. "But I Know it When I See it: An Economic Analysis of Vague Rules," available at SSRN:

http://ssrn.com/abstract=218968 or http://dx.doi.org/10.2139/ssrn.218968.

Frank, Robert H. 1988. Passions within reason: The strategic role of the emotions. New York: Norton.

Garcia, Stephen M., Patricia Chen, and Matthew T. Gordon. (2014"The letter versus the spirit of the law: A lay perspective on culpability." 9(5) Judgment and Decision Making 479-490.

Garoupa, Nuno. 1997. "The Theory of Optimal Law Enforcement," 11 Journal of Economic Surveys 267-95.

(2003), "Behavioral Economic Analysis of Crime: A Critical Review," 15

European Journal of Law and Economics 5-15.

Gibbons, Robert and Rebecca Henderson. 2013. "What Do Managers Do? Exploring Persistent Performance Differences Among Seemingly Similar Enterprises” in R. Gibbons and J. Roberts, eds., Handbook of Organizational Economics, 680-731. Princeton: Princeton University Press.

Guttel, Ehud and Alon Harel. 2008. "Uncertainty Revisited: Legal Prediction and Legal Postdiction," 107 Michigan Law Review 467-99

Haisley, Emily C. and Roberto A. Weber. 2010. "Self-serving interpretations of ambiguity in other-regarding behavior," 68 Games and Economic Behavior 614-25.

Holmstrom, Bengt and Paul Milgrom. 1991. "Multitask Principal-Agent Analyses: Incentive Contracts, Asset Ownership, and Job Design," 7 Journal of Law, Economics, \& Organization (Special Issue, January 1991) 24-52

Hsee, Chistopher K. 1995. "Elastic Justification: How Tempting but Task-Irrelevant Factors Influence Decisions," 62 Organizational Behavior and Human Decision Processes 330-337.

Kahan, Dan M. 1997. "Ignorance of the Law Is an Excuse - But Only for the Virtuous," 96 Michigan Law Review 127-54.

Kaplow, Louis. 1992. "Rules versus Standards: An Economic Analysis," 42 Duke Law Journal 557-629.

Kaplow, Louis and Steven Shavell. 2007. "Moral Rules, the Moral Sentiments, and Behavior: Toward a Theory of an Optimal Moral System," 115 Journal of Political Economy 494-514.

Khanna, V. S. 1996. “Corporate Criminal Liability: What Purpose Does It Serve?,” 109 Harvard Law Review 1477-1534. 
Latham, Gary P., and Gary A. Yukl, G. 1975. "Assigned versus participative goal setting with educated and uneducated woods workers," 60 Journal of Applied Psychology 299302.

Lazear, Edward P. 2000. "The Power of Incentives," 90 American Economic Review 410-14.

Logue, Kyle D. 2007. “Optimal Tax Compliance and Penalties When the Law Is Uncertain,” 27 Virginia Tax Review 241-96.

Marshall, M., and S. Harrison. 2005. "It's about more than money: financial incentives and internal motivation," 14(1) Quality and Safety in Health Care 4-5.

Miller, Alan D. and Ronen Perry. 2012. "Good Faith Performance," 98 Iowa Law Review 689-745.

Moore, Celia, James R. Detert, Linda Klebe Treviño, Vicki L. Baker, and David M.

Mayer. 2012. "Why Employees Do Bad Things: Moral Disengagement and Unethical

Organizational Behavior,” 65 Personnel Psychology 1-48.

Osterloh, Margit and Bruno S. 2013. "Motivation governance," in Handbook of Economic Organization: Integrating Economic and Organization Theory (chapter 2), Anna Grandori (ed.). Cheltenham, UK: Edward Elgar, 26-40.

Parchomovsky, Gideon and Alex Stein. 2014. 114 Columbia Law Review (forthcoming) (draft of March 15, 2014) Cardozo Legal Studies Research Paper No. 421; U of Penn Law School, Public Law Research Paper No. 14-7. Available at SSRN: http://ssrn.com/abstract=2412045.

Polinsky, A.M., and S. Shavell. 2000. "The Economic Theory of Public Enforcement of Law," Journal of Economic Literature, 38(1), 45-76.

Poppo, Laura, \& Todd R. Zenger. 2000. "Substitutes or complements? Exploring the Relationship between Formal Contracts and Relational Governance" (April 17, 2000). Available at SSRN: http://ssrn.com/abstract=223518 or http://dx.doi.org/10.2139/ssrn.223518.

Prendergast, Canice. 1999. “The Provision of Incentives in Firms,” 37 Journal of Economic Literature 7-63Scalia, Antonin.1989. "The Rule of Law as a Law of Rules," 56 University of Chicago Law Review 1175-88.

Schlag, Pierre J. 1985."Rules and Standards," 33 UCLA Law Review 379-430.

Schwartz, Alan and Robert E. Scott. 1995. "Political Economy of Private Legislatures," 143 University of Pennsylvania Law Review 595-654. 
Seijts, Gerard H. and Gary P. Latham. 2001. "The effect of distal learning, outcome, and proximal goals on a moderately complex task," 22 Journal of Organizational Behavior 291-307.

Shavell, Steven. 2002. "Law versus Morality as Regulators of Conduct," 4 American Law and Economics Review 227-57.

Shiffrin, Seana Valentine. 2010. "Inducing Moral Deliberation: On the Occasional Virtues of Fog," 123 Harvard Law Review 1214-47.

Sunstein, Cass R. 1995. "Problems with Rules," 83 California Law Review 953-1026.

Tenbrunsel, Ann E. and David M. Messick, 1999. "Sanctioning Systems, Decision Frames, and Cooperation," 44 Administrative Science Quarterly 684-707.

Tyler, Tom R. and Jeffrey Fagan. 2008. "Legitimacy and Cooperation: Why Do People Help the Police Fight Crime in their Communities?," 6 Ohio State Journal of Criminal Law 231-75.

Tyler, Tom R. 2006. Why People Obey the Law. Princeton: Princeton University Press.

Wood, Robert E., Anthony J. Mento, and Edwin A. Locke. 1987. "Task complexity as a moderator of goal effects: A meta-analysis," 72 Journal of applied psychology 416-25. 


\section{Document for Editing}

What, then, are the general justifications for a legal institution that gives exclusive rights to persons over the things they $\mathbf{o w n}^{2}$ A wide variety of justifications for private property have been offered. We will mention five ${ }^{2}$.

First, the institution of property provides an effective way of managing societies ${ }^{9}$ resources. We can imagine a variety of techniques for managing resources, ranging from governments bureaucracies to local customs to a system of might-makes-right. The property strategy for resource management can be seen as one that delegates neardictatorial powers over particular resources to individual owner-managers, which powers are then backed up the $\mathbf{4}^{4}$ authority of the state. This strategy, to a greater degree than government bureaucracy ${ }^{2}$ allows for decentralization in the management of resources, and permit ${ }^{3}$ the owner-managers to specialize in developing the knowledge and skills pertinent to their particular resource. The decentralized nature of property also permits experimentation with new uses and techniques for managing resources, rendering it more dynamic than a consensus-based system of local custom. And, so long the $\mathbf{e}^{4}$ state provides a sufficient degree of security for ownership, the property strategy $\operatorname{are}^{3}$ more stable and requires fewer expenditures on defensive measures than does might-makes-right system.

Third $^{5}$, the institution of property provides a powerful set of incentives for persons to make investments in and engage in effective management of the resources they control. A homey way of expressing this is that property allows the owners to reap where they have sown. Farmers who own land, for example, can decide what kind of seeds to plant, how much effort to put into cultivating them, and when and how to harvest 
the crops, knowing that the effort and skill they put into the process will be reflected in the yield they ultimately obtain ${ }^{2}$ Other forms of resource management create much less incentive to expend these kinds of efforts to make productive use of resources, because they provide no assurance that those who put in effort to improve the resource will be able to appropriate the fruits of their efforts. This is because no one is in a position to exclude others from interfering with or seeking to capture the benefits of their efforts.

Third, the institution of property facilitates the making of contracts regarding the use and control of resources. In order to contract for the exchange of or modifications to the use of resources, it is necessary to know who controls what resources and, hence, who may make contracts with respect to those resources. Property gives us the answer to these questions. Two types of contracts regarding property were $^{1}$ especially important. One is the exchange of property rights. Suppose I own Blackacre but is ${ }^{\mathbf{3}}$ too old and tired to make much use of it. If I can enter into a contract to sell it to someone else, then this resource may be used more effectively, making society better off. Another is a contract modifying the use of property. If my neighbor is using their ${ }^{6}$ property in a way that cause $^{3}$ me discomfort or irritation, one solution is to enter into a contract with the neighbor in which he or she promises to desist from this use.

Fourth, property is an important source of individual autonomy. Property provides the material means for individuals to achieve a degree of independence from others. By giving individuals control over resources, it allows them to control the direction of their lives. Particular items of property may also be critical to personal identity or to the development of individual personality. Many peoples' identity is closely wrapped up with 
their homes. For others, particular shops or factories may be vital to how they see themselves. Most of us have books, photos, memorabilia, items of clothing, or collections of things to which we attach significance, and where ${ }^{5}$ we would be pained to lose.

Fourth $^{\mathbf{5}}$, property $\mathbf{a r e}^{\mathbf{3}}$ important to the preservation of liberty. Morris Cohen once written $^{1}$ that property is a form of sovereignty; the right to exclude others from things is source of power over other people. This is true, but it also means that if the ownership of property is distributed widely enough, then property ownership can be a source of countervailing power to the power of the government-or the power of other property owners. Checks and balances are thought to be a vital to preserving liberty, and dispersed property ownership provide $\mathbf{3}^{\mathbf{3}}$ an important source of checks and balances. For example private property allows individuals to organize opposition parties and distribute literature critical of the government; if the government controls all the resources it is easy to squelch dissent. And, property allow ${ }^{3}$ unpopular minorities to resist threats from the government to cut off government-granted benefit ${ }^{8}$ or employment.

Although property has been applauded for these positive functions, certain general concerns have also been raised by the institution of property.

One pervasive problem goes by the name "externalities." The private property strategy entails dividing the world $\mathbf{d o w n}^{\mathbf{5}}$ into separate parcels of land and discrete objects personal $^{4}$ property, each with its individual owner. But the owner-managers of these individualized units of property may uses $^{1}$ them in ways that have spillover effects for the owner-managers of other units of property. Spillover effects that had $\mathbf{~}^{\mathbf{1}}$ adverse consequences for others, known as negative externalities, $\operatorname{are~particular}^{4}$ matter of concern. A can use his land in a way that generates pollution damaging to his neighbor B. 
Or $\mathrm{C}$ can allow her car to deteriorate into an unsafe condition, posing a danger on the road to D and other drivers. In fact, the very strategy of allowing owners to appropriate the losses $\mathbf{5}^{\mathbf{5}}$ from their property creates an incentive to try to foist as many of the costs associated with property as possible onto someone else. Any set of legal rules governing property will thus have come $\mathbf{4}^{4}$ up with strategies for trying to control negative externalities.

Another concern about property is monopoly. Property, by its very nature, confers a monopoly of control on someone with respect to a particular resource. Every property right is in this sense a monopoly right. Ordinarily, this is of concern ${ }^{4}$. For example each farmer has a monopoly on his or her own land. But if there are thousands of farmers producing a substantially identical commodity $-\mathbf{s a y}^{2}$ wheat - there will be vigorous competition among the farmers in the market for wheat, and the monopoly each farmer has over his or her own production facilities will have no effect on the price that consumers must pay for wheat. In other circumstances, however ${ }^{2}$ granting property rights can create monopolies that do have troublesome social consequences. For example, if I own the only piece of land on which it is feasible to build a bridge across a river, this may give me a monopoly on river-crossings, and with it the power to extract large polls ${ }^{\mathbf{5}}$ from the public for the privilege of using the bridge. Similarly ${ }^{2}$ the award of patent rights or copyrights may in certain circumstances allow the owners of these rights to extract very large payments from the public, if there are no good substitutes for the thing they have created. This concern therefore suggested ${ }^{1}$ that the property strategy will be becoming ${ }^{\mathbf{1}}$ problematic insofar as the monopoly rights conferred by property confess ${ }^{5}$ with a distinct 
market for particular goods or services. It may be necessary in these circumstances to modify property rights by applying antitrust laws or some form of regulation ${ }^{2}$

Another concern about property is that it leads to commodification of values and social relations. Property conceives of the world in terms of owners dominating or controlling objects. Many people resist thinking this way about their bodies, their intimate relations, their networks of friends and colleagues ${ }^{2}$ their pets, and so forth. The concern here is with the scope or domain of property rights. The more we extend the sphere of property, the more we thought ${ }^{1}$ about the world in terms of owner-object relations. Insofar as it is important to preserve a sphere of life that is organized according to different principles, then we must have exercised ${ }^{\mathbf{1}}$ caution about how far the system of property rights extends.

Finally, property have $\mathbf{e}^{\mathbf{3}}$ long been attacked on the ground that it promoting ${ }^{\mathbf{1}}$ inequality. Property, at least if it is well managed, tend $\mathbf{3}^{\mathbf{3}}$ to beget more property. This is because property, by allowing the $\operatorname{land}^{\mathbf{5}}$ to exclude others, permitted ${ }^{\mathbf{1}}$ the owner to capture the fruits of the property, to reap what have $\mathbf{e}^{3}$ been sowed. Much of the captured "fruit" is attributable the skill and industry of the owner-but not all. Some is attributable to rising demand for resources generally, and to sheer luck. The component that can be ascribed to luck or general conditions of scarcity represents a kind of built-in multiplier whereby those who have property get more property, without regard to them ${ }^{6}$ individual desert. If we combine this with a general right of inheritance, then a robust system of private property can create conditions where the rich generally get richer. This is not to say that abolishing property would create greater equality. Communist systems was ${ }^{3}$ notorious for providing special perks for party leaders that gave them lavish ${ }^{4}$ lifestyle 
for $^{5}$ beyond what ordinary workers could aspire enjoy. But, it does suggest a rationale for imposing higher burdens of taxation on those with significant property to offset the dynamic tendency toward ever greater inequality ${ }^{2}$ Whether this greater burden should be greater than proportionate with wealth or income (i.e. progressive), and so ${ }^{4}$, how much so, has ${ }^{3}$ been a topic of lively debate - as have the question of whether to use taxes or the rules of property itself to achieve distributive ends.

1=Verb tense (10); 2=Punctuation (10); 3=Subject-Verb Agreement (12); 4=Missing words (8); 5=Meaning of words/sentences (9); 6=Pronoun Agreement Error (2); $7=$ Incorrect article usage (1); 8=Singular/Plural (1); 9=Improper Apostrophe Usage (1) 